\title{
A IMPORTÂNCIA EM DESENVOLVER O CÉREBRO QUE DIZ AINDA NA INFÂNCIA
}

\author{
Nathalia Leandra Ribeiro ${ }^{1}$
}

RESUMO: Este artigo apresenta uma breve análise do livro "O Cérebro Que Diz Sim" de Daniel J. Siegel e Tina Payne Bryson. As quatro principais características do Cérebro Que Diz Sim são: equilíbrio, resiliência, percepção e empatia. Estas serão discutidas em detalhes, juntamente com uma introdução de como os pais podem contribuir para esse estágio de desenvolvimento.

PALAVRAS-CHAVE: Infância. Equilíbrio. Resiliência. Percepção. Empatia.

ABSTRACT: This article presents a brief analysis of the book "The Yes Brain" by Daniel J. Siegel and Tina Payne Bryson. The four main characteristics of "The Yes Brain": balance, resilience, perception, and empathy, will all be discussed in detail along with an introduction to how parents can contribute to this stage of development.

KEY-WORDS: Childhood. Balance. Resilience. Perception. Empathy.

Este trabalho apresenta uma análise do livro "O Cérebro Que Diz Sim” de Daniel J. Siegel $^{2}$ e Tina Payne Bryson ${ }^{3}$. Esta obra é um dos maiores manuais para pais e educadores que querem ensinar seus filhos/alunos a lidarem com novos desafios e oportunidades que aparecem no decorrer da vida. As técnicas ensinadas na obra de Siegel e Bryson mostram como ajudar as crianças a serem mais flexíveis, dispostas a arriscar, explorar, ter maior capacidade de assimilação, ser menos rígidas (teimosas) e mais resilientes diante das adversidades. O cérebro que diz sim ao mundo mesmo em situações desfavoráveis, é um cérebro com maior equilíbrio emocional.

\footnotetext{
${ }^{1}$ Formada em Letras pela PUC-GO e em Pedagogia pela UVA. É professora de educação infantil há mais de oito anos, foi devido a sua atuação em sala de aula que ela percebeu a necessidade em ajudar famílias nas intervenções emocionais e sociais das crianças. nathalialeandra91@hotmail.com

2 Daniel J. Siegel é formado em medicina pela Universidade Harvard e pós graduado pela Universidade da California (UCLA). Atua como professor de psiquiatria clínica na UCLA. É codiretor e fundador do centro de pesquisas sobre consciência e Atenção Plena e é diretor-executivo do Instituto Mindsight. Além de professor, ele atua como palestrante e escritor ajudando pais do mundo inteiro.

${ }^{3}$ Tina Payne Bryson é formada pela Universidade de Baylor e PhD pela Universidade da California do Sul. Intitula-se antes de qualquer título, como mãe. Ela é psicoterapeuta de crianças e adolescentes, diretora no setor de Educação de Filhos do Instituto Mindsight. É autora de vários livros e palestrante especialista em desenvolvimento infantil.
} 
Os adultos envolvidos no desenvolvimento infantil têm grande peso sobre o equilíbrio emocional da criança, sendo assim, os pais são os que demandam maior responsabilidade neste quesito. Tudo o que os pais precisam para ajudar a substituir o Cérebro Que Diz Não pelo Cérebro Que Diz Sim é a interação cotidiana de forma equilibrada.

Através da interação, os pais darão aos seus filhos uma orientação interior para que eles enfrentem os desafios da vida com segurança e entusiasmo. Os pais têm o papel de ensinarem aos filhos como desenvolverem a parte cerebral responsável por manter um estado neurológico em que ajude as crianças a encararem o mundo de forma receptiva, resiliente, empática e autêntica.

O Cérebro Que Diz Sim é criado pela atividade neural que envolve determinada região do cérebro que se chama córtex pré-frontal, uma área que se liga a muitas outras regiões, lida com o pensamento superior e promove a curiosidade, a resiliência, a compaixão, a percepção, a aceitação de ideias novas, a solução de problemas e até a moralidade. (SIEGEL e BRYSON, 2019, p. 18).

As crianças precisam de oportunidades e ferramentas para saberem como voltar ao estado Cérebro Que Diz Sim. Crianças pequenas, com três anos ou menos, irão se frustrar com maior intensidade/frequência, e consequentemente, entrar com mais facilidade no estado do Cérebro Que Diz Não. Desta forma, elas precisarão da mediação de um adulto para serem menos reativas. À medida que elas crescem os pais podem ajudá-las a desenvolver a capacidade de controlaremse sozinhas. Assim, cada vez mais o "não" dará espaço ao "sim”.

\begin{abstract}
Não se trata de dizer "sim" aos filhos o tempo todo. Não se trata de ser permissivo, de ceder, de protegê-los das decepções ou salvá-los de situações difíceis. Nem de criar filhos submissos, que copiam roboticamente os pais sem pensar por conta própria. Ao contrário, trata-se de ajudar as crianças a perceber quem são e em que pessoas estão se transformando, trata-se de ensiná-las que podem superar as decepções e derrotas e que podem escolher uma vida cheia de conexões e significados. (SIEGEL e BRYSON, 2019, p. 21)
\end{abstract}

O Cérebro Que Diz Sim não promete felicidade o tempo todo, isso seria impossível. Com ele as crianças - adolescentes e adultos - ressignificarão a definição de alegria. Em meio ao caos aqueles que utilizarem as estratégias do Cérebro Que Diz Sim conseguirão ser flexíveis para se adaptarem ou readaptarem ao novo, sentirão certeza das suas decisões e emergirão dessas situações mais fortes e sábios. Além de entrarem em contato com o seu "eu", os outros e o 
mundo. Um Cérebro Que Diz Sim não olha apenas para sua vida interior, ele se preocupa com os que estão a sua volta.

O Cérebro Que Diz Não é muito mais fácil de ser construído, ainda mais quando se leva em consideração as escolas tradicionais com testes padronizados e memorização como estratégia de ensino. Somando a isso tem-se as agendas lotadas e a mídia digital. Sim, cultivar o Cérebro Que Diz Sim é ainda mais importante analisando este cenário. Porém, pais, não se desesperem em tentarem a perfeição para seus filhos, estejam emocionalmente disponíveis a eles e permitam que o desenvolvimento aconteça.

A conexão entre pais e filhos ajudará as crianças a desenvolverem um cérebro integrado. Este terá mais facilidade para solucionar situações difíceis demonstrando receptividade ao invés de reatividade (característica do Cérebro Que Diz Não). Os pais podem criar e/ou fortalecer conexões importantes com seus filhos:

(...) se você estiver lendo com seu filho e perguntar: "Por que você acha que essa menininha ficou triste?", estará lhe dando a chance de criar e fortalecer a empatia e o circuito de engajamento social em seu cérebro. (...) Dando atenção a essa emoção, você estará criando o circuito de autoconhecimento. E, quando você conta piadas ou charadas, está dando atenção ao humor e a logica, ajudando a desenvolver esses aspectos na personalidade de seus filhos. (...) Expor seus filhos a humilhação e a críticas excessivas abre novas vias neurais que afetarão a autoestima deles. (SIEGEL e BRYSON, 2019, p. 29)

O Cérebro Que Diz Sim é baseado em quatro fundamentos: equilíbrio, resiliência, percepção e empatia. Para tanto, dividimos o trabalho em quatro partes, cada uma destinada a um fundamento.

\section{O cérebro equilibrado}

Um cérebro desequilibrado não é capaz de controlar suas emoções e ações em um momento em que O Cérebro Que Diz Não está se acionando. Em crianças menores é mais comum observar comportamentos como bater, chutar, morder, atirar coisas etc. Em crianças mais velhas, essas ações ainda podem se fazer presentes, porém elas também já conseguem usar, inconscientemente, uma psicologia para ferir os pais através de falas e expressões. Com os mais velhos, ainda existe a possibilidade de eles bloquearem qualquer demonstração de sentimento, 
preferindo o isolamento. É preocupante caso os pais não percebam perturbação ou perda de controle em algum momento da vida de seus filhos, pois se eles levarem esta prática para suas vidas adultas possibilitarão o bloqueio emocional e a sensação de vitalidade que brota de uma vida emocionalmente equilibrada.

No momento em que a criança está emocionalmente descontrolada cabe ao adulto envolvido ajudá-la a recuperar o controle da situação. Essa ajuda dar-se-á por meio de uma presença amorosa e tranquilizadora. E só depois do equilíbrio retomado é que a o diálogo sobre a postura da criança será colocado em pauta. Nessa conversa o adulto retomará o comportamento que a criança teve, e explicitará quais são suas expectativas no futuro caso uma situação semelhante venha a acontecer.

Os autores fazem menção a três zonas em que o cérebro pode se encontrar em determinada situação de equilíbrio ou desequilíbrio, são elas: zona vermelha, zona verde e zona azul. Quando a pessoa está no estado de Cérebro Que Diz Sim ela está na zona verde utilizando a janela da tolerância - expressão criada por Siegel para descrever a amplitude de ativação do cérebro dentro da qual podemos funcionar bem. Na zona vermelha, é onde os acessos de raiva acontecem devido a hiper estimulação do sistema nervoso. Já na zona azul, a retração é característica marcante, a pessoa prefere se distanciar ou dissociar da situação. A dissociação é mais comum em históricos de traumas.

É normal, vez ou outra, observar seu filho na zona vermelha ou na zona azul, e é até importante que eles experimentem as sensações trazidas por esses sentimentos. Mais importante que vivenciar essas emoções é conseguir emergir de uma dessas zonas para zona verde novamente, através de maneiras novas e criativas. A conexão entre pais e filhos é a maneira mais eficaz de ajudar uma criança a voltar para a zona verde. Para que a conexão entre pais e filhos seja eficiente em um momento de descontrole emocional, esta precisa, antes, ser estabelecida enquanto a criança estiver na zona verde, nas trocas sociais diárias.

Muitas vezes há falhas nessas trocas sociais, alguns pais distanciam-se de seus filhos emocionalmente por achar que minimizando ou criticando seus sentimentos eles serão mais fortes. É comum ver pais imitando o choro dos filhos, mal sabem eles que ao reproduzirem este comportamento estão validando a ação do filho perante uma dificuldade. Devido a essa e outras 
posturas dos pais "as crianças sentem-se abandonadas ou são obrigadas a enfrentar problemas para os quais não estão preparadas em termos de desenvolvimento”. (SIEGEL e BRYSON, 2019, p. 29)

$\mathrm{Na}$ adolescência essa minimização de sentimentos por parte dos pais será ainda mais problemática. Pois o cérebro internalizará que sentimentos não precisam ser compartilhados, pois assim, críticas serão evitadas. Então, os adolescentes passam a esconder seus verdadeiros sentimentos dos pais e a permanecer em uma zona desregulada, sem saber como retomar a zona verde, dando abertura a depressão e outras doenças psiquiátricas.

Por outro lado, existem os pais que não respeitam a individualidade dos filhos, os famosos pais helicópteros, expressão usada pela primeira vez no livro Parents and Teenagers de Dr. Haim Ginott. No qual adolescentes disseram que seus pais os vigiavam como um helicóptero. É devido ao amor gigantesco pelos filhos que muitos pais excedem na interação com os filhos e começam a cumprir simples tarefas para, de certa forma, privar os filhos do sofrimento. Entre ser um pai helicóptero ou um pai que minimiza emocionalmente o filho, escolha ser o helicóptero, mas trabalhe para ser aquele que saiba agir na medida certa.

É por causa de nosso profundo amor por eles que queremos protegê-los, mas sua competência será maior se permitimos que o amor nos de coragem para nos sentirmos suficientemente fortes para deixar que eles descubram sua própria força. (SIEGEL e BRYSON, 2019, p. 66)

Os pais podem ainda contribuir para o equilíbrio emocional de seus filhos equilibrando suas agendas de atividades. Este é um dos pontos essenciais deste artigo, aqui será discutido a importância do brincar no desenvolvimento emocional de seus filhos, mais importante que brincar é o brincar de forma livre. O brincar livre é o momento em que as crianças estão brincando sem possuírem brinquedos prontos, é quando elas estão em contato com a natureza criando, imaginando, interagindo com os outros (espaço e pessoas) sem medo de julgamento e sem precisar cumprir regras, como em um jogo, seja de tabuleiro ou um esporte. É através do brincar livre que a criança será capaz de libertar e explorar sua imaginação, regulando suas emoções, melhorando a linguagem e a capacidade de resolução de problemas, além do 
desenvolvimento social. Hoje, esta forma de brincar está entrando em extinção, e caso isso realmente aconteça os danos para O Cérebro Que Diz Sim serão imensuráveis pois:

(...) brincar oferece também vantagens emocionais e psicológicas, ajudando a criar um cérebro equilibrado. Quando brincam, as crianças adquirem prática em TODAS as qualidades do Cérebro Que Diz Sim, como lidar com a decepção, manter a atenção e dar sentido ao seu mundo. Ensaiam papéis e dominam os medos e sentimentos de impotência. Adquirem equilíbrio emocional e resiliência, e desenvolvem a capacidade de suportar a frustração quando alguma coisa não dá certo. Tudo porque tem permissão para brincar. (SIEGEL e BRYSON, 2019, p. 72)

Além do brincar e do brincar livre as crianças também precisam ter o sono equilibrado. $\mathrm{O}$ sono é a higiene do cérebro, pois é através dele que será possível que o cérebro libere as toxinas responsáveis pela queima neurológica diária. A pessoa que cumpre recomendação de sono terá uma zona verde e uma janela da tolerância alargadas, serão mais capazes de controlar suas emoções e resolver seus problemas. É unânime os pais reclamarem do comportamento de seus filhos quando estes estão cansados, muitas vezes os pais têm parcela de culpa nesse cansado, pois devido a agenda lotada de atividades o sono é o sacrificado da vez.

Siegel e David Rock criaram o "prato da mente saudável”. Este prato é composto por uma divisão de tempo de atividades essenciais para O Cérebro Que Diz Sim: tempo de concentração, tempo de brincar, tempo de relacionamento, tempo de exercício físico, tempo interior, tempo de devanear e tempo de dormir. Seguindo e respeitando o prato da mente saudável os pais contribuirão nas conexões de seus filhos nas diferentes atividades mentais que eles são capazes de fazer. É importante que as crianças vivenciem diariamente os sete tempos citados acima.

\section{O cérebro resiliente}

O segundo fundamento para um Cérebro Que Diz Sim é a resiliência. Ser resiliente consiste em recuperar o controle da situação. É voltar da zona vermelha ou azul para a zona verde. É recuperar a harmonia dentro da janela da tolerância. O objetivo do Cérebro Que Diz Sim a curto prazo é ser equilibrado e a longo prazo é ser resiliente. 
Quando uma criança apresenta um mau comportamento os pais, ao invés, de anularem esse comportamento, através de recompensas ou ameaças, precisam dar ferramentas para que seus filhos consigam construir capacidades para retornarem ao estado de equilíbrio de forma resiliente. Os pais precisam analisar profundamente qual a dificuldade de seu filho para então criar estratégias para solucionar o problema.

Siegel e Bryson citam como exemplo uma criança que tinha dificuldade em esperar sua vez e a partilhar seus pertences. Sob a lente do Cérebro Que Diz Sim, a mãe planejou atividades em que seu filho hora fingia ser o professor, hora era o aluno, ou o colega. Ela também criou histórias nas quais seu filho era convidado a participar ativamente na resolução dos conflitos dos personagens, representados por seus bonecos de super-heróis. Dessa forma o mau comportamento não foi anulado e sim reconhecido, fazendo com que a criança adquirisse estratégias para resolvê-lo e voltasse ao seu estado de equilíbrio de forma resiliente e expandindo a janela da tolerância.

Expandir a janela da tolerância é, em parte, permitir que as crianças enfrentem adversidades, decepções e outras emoções negativas, e até mesmo que fracassem. É assim que elas criam coragem e perseverança. (...) momentos e tempos difíceis são inevitáveis. (SIEGEL e BRYSON, 2019, p. 97)

Os pais precisam permitir que os filhos passem por situações difíceis, como o fracasso. As privações desse sentimento implicarão, de má forma, na construção da resiliência. Ao invés de solucionar o problema para os filhos, os pais precisam se mostrar emocionalmente conectados com suas crias, oferecendo o conforto necessário e mostrando a eles que por mais difícil que uma situação seja, os filhos poderão enfrentá-las e recuperar-se, e mais, se preciso for os pais estarão lá dando o apoio necessário, nada além do necessário.

Então, em vez de ir a seu socorro [crianças] e protegê-las de qualquer emoção ou situação problemática, é importante passar por esses momentos com elas, ajudando-as a criar resiliência para enfrentar contratempos e tomar decisões acertadas em meio a uma tempestade emocional. Desejamos que elas interiorizem nossa mensagem: "Estou aqui. Você vai conseguir. Sei que é difícil, mas você pode. Eu estou aqui". É assim que expandimos a zona verde: ensinando-as com amor que podem conviver com a frustração e o fracasso, passar por eles e sair mais fortes e mais sábios. (SIEGEL e BRYSON, 2019, p. 98) 
Todo crescimento emocional precisa ser equilibrado, sendo assim, os pais não podem resolver tudo para seus filhos, mas eles, os pais, também não podem pressioná-los para a resolução de um problema, além do que as crianças podem suportar. Se os desafios forem maiores que a capacidade de resolução de seus filhos os pais devem dar apoio. Os pais também podem mesclar sua postura. Em uma situação difícil, mas não o bastante para precisar intervir, os pais devem impulsionar emocionalmente os filhos para que eles encontrem a resolução, em outros momentos os pais podem/devem dar apoio, o colo propriamente dito, propondo pequenos passos em direção ao objetivo.

(...) lembre-se de que cada criança é diferente e complexa e, em cada situação, decida o que é melhor para essa criança única nesse determinado momento e perceba o que pode gerar crescimento e expansão daquilo que são capazes de fazer. Isso é resiliência. (SIEGEL e BRYSON, 2019, p. 104)

Siegel e Bryson apresentam duas estratégias para ajudar aos pais criarem resiliência em seus filhos. A primeira delas consiste em oferecer às crianças a ligação segura, na qual eles se sentirão seguros e protegidos, principalmente nos momentos que estão entrando na zona vermelha ou na zona azul. A segunda estratégia consiste em ensinar aos filhos a capacidade de "visão mental". Este termo foi criado por Siegel e significa "a capacidade de perceber e compreender a mente - nossa e dos outros. É uma maneira de sentir e tirar sentido da vida mental interior que todos temos. Inclui três aspectos: percepção, empatia e interação."

\section{O cérebro perceptivo}

Comparando os quatro fundamentos do Cérebro Que Diz Sim, equilíbrio, resiliência, percepção e empatia, é sobre a percepção que menos pensamos. De forma resumida, a percepção é a capacidade que a pessoa tem de olhar para dentro e se entender, e então usar o que aprendeu para controlar melhor suas emoções e circunstâncias (SIEGEL E BRYSON, 2019).

A disciplina é aliada importantíssima para a criação e desenvolvimento da percepção em crianças, e até mesmo em adultos. Na obra Disciplina sem drama de Siegel e Bryson é explicado que: 
[disciplina] não se baseia em castigar, mas em ensinar - visa dois objetivos primordiais: (1) obter cooperação em curto prazo, fazendo cessar o mau comportamento, e (2) criar capacidades e fomentar, no cérebro de nossos filhos, conexões que os ajudarão a tomar decisões melhores e se controlar melhor no futuro. (SIEGEL e BRYSON, 2015)

A percepção é uma habilidade indispensável para que o indivíduo desfrute de uma vida criativa, feliz e com sentido. É através dela que ele poderá observar atentamente o seu interior e não se sentirá impotente diante de sentimentos e circunstâncias difíceis. Percebendo o que está acontecendo o indivíduo conseguirá olhar atentamente seu "eu” e tomará decisões conscientes e intencionais.

Para que a pessoa escolha qual a melhor decisão a ser tomada, é preciso que ela pratique a pausa, em seu mais simples significado: "Interrupção breve de um movimento, uma ação, um exercício, um som etc.” (MICHAELIS, 2020). Caso a pausa não seja feita, o resultado será entrar no estado do Cérebro Que Diz Não.

Quando praticamos a flexibilidade e fazemos uma pausa antes de reagir, colocamos um espaço temporal e mental entre o estímulo e a ação. De uma perspectiva neurobiológica, esse espaço mental cria várias possibilidades a serem consideradas. (...) A flexibilidade de reação permite escolher "ser mais sábio possível" naquele momento, com menos estresse e mais felicidade para nós e para as pessoas de nossa vida. (SIEGEL e BRYSON, 2019, p. 131,132)

É importante ressaltar que a percepção não visa interromper ou bloquear sentimentos. Como já foi dito é importante e saudável que as crianças, ou quaisquer indivíduos, vivenciem os diferentes sentimentos. O ponto principal da percepção é estimular melhores decisões depois de uma pequena pausa. É como se, por alguns instantes, você visse a situação problemática como um espectador, analisasse e então decidisse o que fazer. Isso não irá interromper o que você está sentindo, e sim, estimular uma melhor decisão.

Os autores da obra O Cérebro Que Diz Sim demonstram duas estratégias as quais os pais e educadores podem recorrer para ajudar a desenvolver em suas crianças a percepção. A primeira estratégia consiste em reformular o sofrimento de forma que se perceba que o esforço não é algo ruim. Muitos acreditam que se há um caminho mais fácil, essa é a melhor escolha, esta primeira estratégia mostra o contrário, às vezes, o esforço trará um resultado melhor. 
Podemos ensinar aos nossos filhos que a vida é uma jornada de esforço e descoberta, e não sobre capacidade de ter o sucesso facilmente ao alcance da mão. É assim que lhes damos a percepção que gera uma mentalidade de crescimento. Essas são boas lições que as crianças devem aprender. Para enfrentar situações difíceis, você pode estimular uma perspectiva útil fazendo uma simples pergunta para ajudar a desenvolver a percepção das crianças: "Qual esforço você prefere?” (SIEGEL e BRYSON, 2019, p. 136) [Esforçar-se para concretizar algo que você tanto almeja, ou esforçar-se em sofrer por não conseguir alcançar seu objetivo por falta de 'sacrifício'?]

De acordo com essa primeira estratégia, cabe aos pais, principalmente, ajudar a desenvolver e a praticar a pausa antes da ação. Assim, as crianças terão consciência do que estão sentindo e escolherão melhor como interagir com o mundo sem levar em conta apenas o que é mais fácil.

A segunda estratégia para promover um cérebro perceptivo é evitar a erupção do Vulcão Vermelho:

(...) quando qualquer um de nós fica perturbado com alguma coisa, cresce a excitação de nosso sistema nervoso. Sentimos isso no corpo: o coração bate mais rápido, nossa respiração se acelera, nossos músculos se tensionam e a temperatura corporal pode se elevar. Podemos imaginar nossa reação emocional a um estímulo perturbador como uma curva em sino, que com as crianças chamamos de Vulcão Vermelho. (SIEGEL e BRYSON, 2019, p. 140)

Os podem ensinar seus filhos a perceberem quando seus cérebros estão caminhando para a erupção do Vulcão Vermelho, os sinais corporais são evidentes e contribuem para essa percepção. Vendo que estão se aproximando da erupção a pausa deve acontecer para evitar que o cérebro entre na incontrolável zona vermelha, na qual a erupção, por sua vez, irá acontecer.

\section{O cérebro empático}

Este é o último fundamento do Cérebro Que Diz Sim. Uma definição simples de empatia consiste em afirmar que ser empático é sentir com outro ou sentir a experiência do outro e preocupar-se com o que ele está enfrentando. Porém a empatia possui cinco facetas, simbolicamente representa pelos autores como "o diamante da empatia". As facetas desse diamante são: 
Tomada de perspectiva: ver o mundo através dos olhos dos outros; Ressonância emocional: sentir os sentimentos do outro;

Empatia cognitiva: entender, ou adquirir intelectualmente, a experiencia do outro;

Empatia compassiva: sentir o sofrimento e desejar reduzi-lo;

Alegria empática: alegrar-se com a felicidade e o bem-estar do outro. (SIEGEL e BRYSON, 2019, p. 158)

É devido a empatia que a criança, ou qualquer indivíduo, será capaz de tomar decisões morais e éticas, pois se o sentimento de alguém tem relevância ao indivíduo que tomará uma decisão, as chances de ele mentir, roubar ou oprimir serão reduzidas quase a zero.

Assim como as outras capacidades do Cérebro Que Diz Sim, a empatia deve ser aprendida. Esse aprendizado acontecerá através do exemplo dos pais com a própria criança e com o mundo, por meio de cuidado, consideração e amor. Conversas sobre o que é ser empático são importantes, mas mais que isso, a atitude dos pais terá maior peso sobre a construção desse fundamento.

A empatia é internalizada pelas crianças quando seus pais estão verdadeiramente com elas. Momentos como os de leitura, jogos, práticas de esportes, conversas, brincadeiras ou simplesmente quando estão juntos sentindo o coração um do um do outro são exemplos de momentos válidos para a construção da empatia. Além da importância dos pais demonstrarem interesse em estar com os filhos é válido interessar-se pelos sentimentos deles. Outra forma de exemplificar esse fundamento aos filhos, é através do trabalho voluntário no qual os pais demonstram interesse pelo sentimento de pessoas que não estão em seu círculo familiar, mas que merecem empatia da mesma forma.

Siegel e Bryson apresentam estratégias de como promover a empatia no cérebro das crianças. Ativar o sistema de engajamento social do cérebro das crianças irá prepará-las para ver situações através da lente da empatia percebendo e captando os sinais verbais e não verbais do outro. Outra forma de construir a empatia é dar as crianças um leque, de exemplos de expressões linguísticas e corporais, no qual elas possam recorrer para verbalizar que estão preocupadas com os sentimentos dos outros.

$\mathrm{E}$, quando as crianças desenvolvem mesmo que seja uma linguagem rudimentar de empatia, preparam-se para relacionamentos muito mais profundos e criam alicerces que lhes permitirão ter uma vida mais rica e significativa quando chegarem a idade adulta. (SIEGEL e BRYSON, 2019, p. 175) 
Ser empático não é apenas entender o que os outros estão sentindo, é preocupa-se com o outro, é perceber que o mundo é interconectado. Perceber que existe essa conexão entre o "eu” e o mundo leva o indivíduo a ter uma vida com mais sentido.

Mesclando os quatro fundamentos do Cérebro Que Diz Sim: equilíbrio, resiliência, percepção e empatia, os pais ou qualquer adulto interessado no desenvolvimento psíquico das crianças poderão guiá-los na construção de capacidades que lhes permitam interagir com seu interior e consequentemente com o mundo exterior. Atingindo sucesso em seu desenvolvimento humano recebendo novos desafios e oportunidades sem aversão, valorizando a curiosidade e a aventura, emergindo das adversidades com sabedoria e olhando para o outro com compaixão.

\section{REFERÊNCIAS}

SIEGEL e BRYSON, O Cérebro Que Diz Sim. São Paulo: Planeta, 2019.

SIEGEL e BRYSON, O cérebro da criança. São Paulo: Casa das Letras, 2017.

SIEGEL e BRYSON, Disciplina sem dramas. São Paulo: Leya, 2015.

GINOTT, Bwetween Parent and Teenager. Hardcover, 1969.

MICHAELIS, Dicionario Michaelis. Melhoramentos, 2020.

BIOGRAFIA de Dr. Daniel J. Siegel. Disponível em: <https://www.drdansiegel.com/about/biography/>. Acesso em 03 de maio de 2020.

BIOGRAFIA de Tina Payne Bryson. Disponível em: <https://www.tinabryson.com/>. Acesso em 03 de maio de 2020. 